\title{
UPAYA PENINGKATAN KUALITAS MIKROBIOLOGI AIR BERSIH DI RSUD SYARIFAH AMBAMI RATO EBU BANGKALAN TAHUN 2017
}

Madina Amalia, Ferry Kriswandana, Ngadino

\begin{abstract}
Rumah sakit merupakan suatu institusi yang memberikan pelayanan kesehatan. Dalam aktivitas rumah sakit, terdapat risiko penimbulan penyakit yang disebabkan oleh interaksi antara orang yang sehat, yang sakit dan beberapa orang yang mempunyai imunitas rendah. Untuk mencegah penularan penyakit dan risiko lingkungan, rumah sakit harus mempunyai program pengendalian seperti yang terdapat pada Permenkes 1204 tahun 2004. Salah satu aspek sanitasi pada rumah sakit adalah air bersih. Peraturan mengenai kualitas air bersih terdapat pada Permenkes 32 tahun 2017. Berdasarkan monitoring kualitas air bersih yang dilakukan oleh Inslatasi Lingkungan RSUD Syamrabu Bangkalan menunjukkan bahwa beberapa point sampling tidak sesuai ( $>50 / 100 \mathrm{~mL}$ sample). Tujuan penelitian ini untuk mengidentifikasi hal- hal yang mempengaruhi kualitas mikrobiologi air bersih.

Sampel diambil tiga kali pada 6 titik sampling di reservoir dan yang paling jauh dari tandon tanah dan tandon atas. Teknik dan manajemen sampling juga dideskripsikan.

Hasil penelitian menunjukkan bahwa pada sampling pertama, 2 dari 6 sampel tidak sesuai dengan baku mutu. Pada sampling kedua, 1 dari 6 sampel tidak sesuai dengan baku mutu. Dan pada sampling ketiga, 4 dari 6 sampel tidak sesuai dengan baku mutu. Teknik dan manajemen sampling setelah diobservasi juga menunjukkan hasil yang buruk, yaitu 50\% dari penilaian dibawah $75 \%$. Hal ini dikarenakan dosis desinfektan kurang optimal dengan debit air yang dihasilkan sehingga nilai total coliform tinggi. Selain itu, tidak pernah ada tes sisa klor dan inspeksi sanitasi oleh instalasi Lingkungan.

Saran yang dapat diberikan untuk RSUD Syamrabu adalah meningkatkan dosis desinfektan yang disesuaikan rata- rata debit air bersih dan merubah alat dan fasilitas pendistribusian air bersih sehingga program air bersih dapat dilaksanakan dengan baik dan efektif.
\end{abstract}

Kata kunci: air bersih, rumah sakit, coliform

\section{Pendahuluan}

Kesehatan masyarakat adalah faktor yang dapat digunakan untuk menilai kondisi kesejahteraan masyarakat. Menurut Etrawati (2012) menyatakan bahwa salah satu teori yang dikembangkan oleh $\mathrm{HL}$ Blum menyatakan bahwa status kesehatan masyarakat dipengaruhi empat faktor yakni faktor keturunan, pelayanan kesehatan, perilaku dan lingkungan. Tiap faktor juga memiliki pengaruh yang berbeda besarannya. Menurut Hapsari, Sari, Pradono (2009) menyatakan bahwa faktor kesehatan lingkungan memiliki pengaruh terbesar yaitu $45 \%$, selanjutnya faktor perilaku $30 \%$, faktor pelayanan kesehatan $20 \%$, dan faktor genetik $5 \%$.

Rumah sakit adalah institusi pelayanan kesehatan yang memiliki peran menyelenggarakan pelayanan kesehatan perorangan secara paripurna Rumah sakit juga melakukan upaya-upaya penyehatan lingkungan. Hal tersebut harus dilakukan karena di dalam rumah sakit terdapat risiko penularan penyakit. Persyaratan kesehatan lingkungan pada rumah sakit di Indonesia diatur pada Permenkes nomor 1204 tahun 2004.

Hasil pemantauan kualitas air bersih di RSUD Syamrabu Bangkalan yang dilakukan oleh instalasi kesehatan lingkungan rumah sakit tersebut ditemukan parameter air bersih yang tidak memenuhi persyaratan berdasar Permenkes nomor 32 tahun 2017 Parameter yang melebihi syarat tersebut adalah parameter mikrobiologi yakni total koliform pada air perpipaan yang hasilnya diatas 50 per $100 \mathrm{~mL}$ sampel.

Bakteri koliform adalah mikroba yang ditemukan dalam sistem pencernaan hewan berdarah panas, di dalam tanah, tanaman, dan di permukaan air. (CDC, 2009). Tujuan dari penelitian ini adalah untuk Mengetahui upaya yang dapat 
dilakukan untuk meningkatkan kualitas mikrobiologi air bersih di RSUD Syamrabu Bangkalan.

\section{Metode Penelitian}

Jenis penelitian yang digunakan dalam penelitian ini adalah metode penelitian evaluasi (evaluation study) deskriptif kuantitatif. Menurut Notoatmodjo (2014:49) penelitian evaluasi adalah suatu penelitian untuk menilai suatu program yang sudah dilakukan dimana hasil dari penelitian ini digunakan untuk perbaikan dan/atau peningkatan program tersebut. Hasil yang dihasilkan akan ditampilkan dalam bentuk angka.

Populasi dalam penelitian ini adalah air bersih di RSUD Syamrabu Bangkalan. Sedangkan sampel air bersih diambil pada enam titik yakni di lima titik terjauh dari masing-masing roof tank dan ground tank ruangan untuk mengetahui apakah proses pengolahan air yang dilakukan dapat menjamin kualitas mikrobiologi hingga titik terjauh tersebut dan satu sampel pada groundtank sebagai reservoir utama. Penentuan jumlah sampel ditentukan berdasar Permenkes nomor 1204 tahun 2004 tentang Kesehatan Lingkungan Rumah Sakit. RS Syamrabu
Bangkalan yang memiliki 339 kamar yang berarti jumlah minimal sampel yang diambil untuk uji mikrobiologi adalah 6 sampel dengan pengulangan tiga kali pada awal bulan, pertengahan, dan akhir bulan untuk mengetahui apakah dosis dan waktu pemberian satu kali desinfektan per bulan mencukupi untuk mendesinfeksi air selama sebulan. Sampling diambil secara steril dan dijaga suhu selama perjalanan $\leq 10^{\circ} \mathrm{C}$ (Da Silva:2010). Sampel kemudian dianalisa menggunakan metode MPN coliform, metode ini memiliki hasil dengan batas kebenaran 95\% (Pandit dan Jyoti:2013).

Observasi dilakukan terhadap aspek teknis dan manajemen penyediaan air bersih di RSUD Syamrabu Bangkalan yang mempengaruhi cemaran kualitas mikrobiologi air bersih.Hasil observasi akan dinyatakan memenuhi syarat jika $\geq 75 \%$ dan tidak memenuhi syarat jika $<75 \%$. Analisa terhadap data dilakukan secara deskriptif per variabel dengan pertimbangan Permenkes nomor 32 tahun 2017 tentang Standar Baku Mutu Kesehatan Lingkungan Dan Persyaratan Kesehatan Air untuk Keperluan Higiene Sanitasi, Kolam Renang, Solus Per Aqua, Dan Pemandian Umum dan Permenkes 1204 tahun 2004 tentang Kesehatan Lingkungan Rumah Sakit.

\section{Hasil dan Pembahasan}

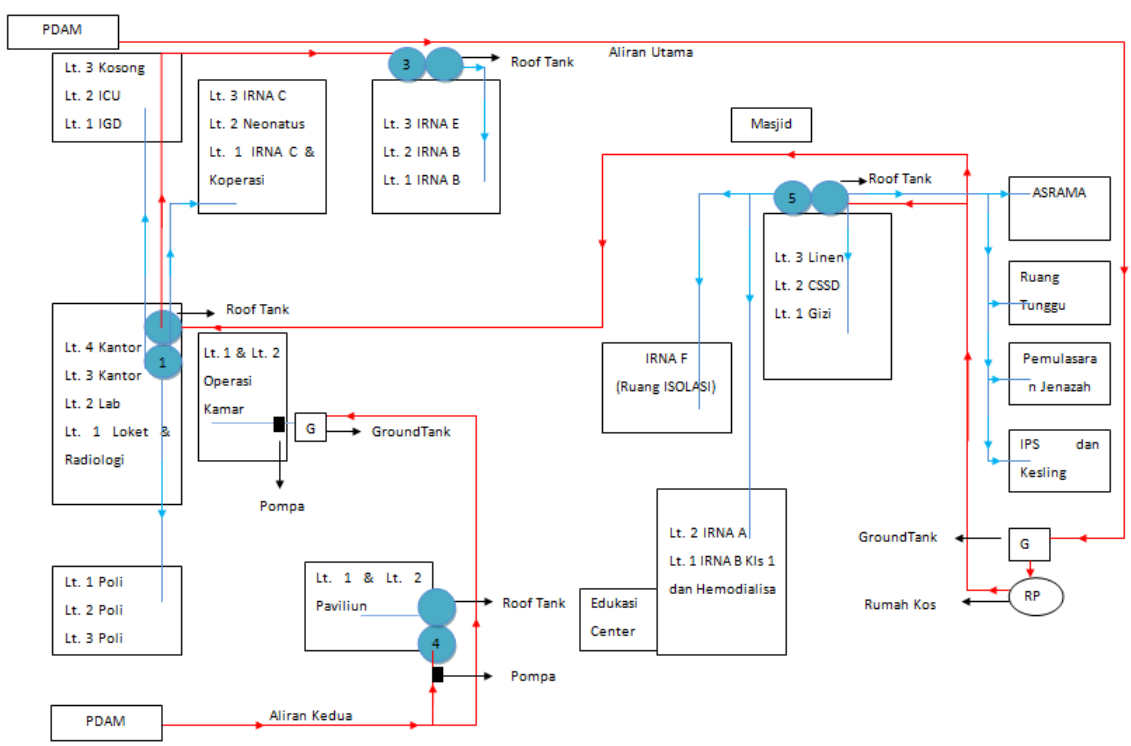

Gambar 1 Denah Aliran Air Bersih RSUD Syamrabu Bangkalan 
Aliran Pertama yang berasal dari air PDAM di sebelah barat rumah sakit. Aliran ini langsung mengarah ke ground tank utama (A) Rumah Sakit. Di ground tank utama terdapat desinfeksi ulang yakni pemberian klorin tablet, jenis klorin tablet yang digunakan adalah TCCA (Trichloroisucyanuric acid) dengan rumus kimia $\mathrm{C}_{3} \mathrm{Cl}_{3} \mathrm{~N}_{3} \mathrm{O}_{3} \quad 90 \%$ berbentuk tablet dengan masing-masing berat tablet adalah 200 gr. Air dari dalam ground tank utama dialir kan ke roof tank di gedung utama (B) dan gedung linen/CSSD/Gizi (C) dengan bantuan empat pompa di rumah pompa. Kemudian roof tank di gedung utama juga mengaliri roof tank lain di gedung Irna (D). Sampling pertama dilakukan 15 Maret 2017, sampling kedua 31 Maret 2017, dan sampling ketiga 5 Juni 2017. Berikut adalah hasil pemeriksaan total koliform pada aliran utama

Tabel 1

HASIL PEMERIKSAAN TOTAL KOLIFORM AIR BERSIH ALIRAN UTAMA

\begin{tabular}{|c|c|c|c|c|c|c|}
\hline No & Sampling & $\begin{array}{c}\text { Titik } \\
\text { Sampling }\end{array}$ & $\begin{array}{c}\text { Hasil } \\
\text { (/100 mL sampel) }\end{array}$ & Jarak & $\begin{array}{c}\text { Batas Maks } \\
\text { (/100 mL } \\
\text { sampel) }\end{array}$ & Ket \\
\hline 1 & \multirow{4}{*}{ Pertama } & A & $<1,8$ & - & 50 & MS \\
\hline 2 & & C & 1600 & 42 & 50 & TMS \\
\hline 3 & & D & $<1,8$ & 48 & 50 & MS \\
\hline 4 & & B & $<1,8$ & 62 & 50 & MS \\
\hline 5 & \multirow{4}{*}{ Kedua } & A & 33 & - & 50 & MS \\
\hline 6 & & C & 49 & 42 & 50 & MS \\
\hline 7 & & D & 49 & 48 & 50 & MS \\
\hline 8 & & B & 17 & 62 & 50 & MS \\
\hline 9 & \multirow{4}{*}{ Ketiga } & A & 49 & - & 50 & MS \\
\hline 10 & & C & 350 & 42 & 50 & TMS \\
\hline 11 & & D & 130 & 48 & 50 & TMS \\
\hline 12 & & $B$ & 130 & 62 & 50 & TMS \\
\hline
\end{tabular}

Dari hasil pemeriksaan dan observasi, maka penyebab cemaran total koliform pada aliran pertama air bersih di RSUD Syamrabu Bangkalan adalah:

1. Ground Tank Utama

Ground tank sebagai sumber air yang mensuplai air ke beberapa gedung harus terlindung kualitas sumber airnya, proses treatment yang dilakukan pada ground tank juga harus efektif dan efisien karena kualitas mikrobiologi air dari sumber air PDAM yang mengalir ke ground tank tidak dapat di pastikan kualitasnya. Desinfeksi sebagai satu satunya treatment yang dilakukan di ground tank belum terukur dosisnya dengan tepat. Padahal salah satu keunggulan klorin sebagai desinfektan adalah dosis sisa yang melindungi air dari pencemaran sepanjang sistem distribusi (Pizzi:2010). Dokumen terkait kegiatan pembersihan ground tank. Dokumen tersebut berupa dokumen prosedur sebagai panduan petugas bekerja dan juga dokumen rekaman (dokumentasi) pekerjaan agar kegiatan tercatat dengan baik dan dapat terpantau.

2. Kran Terjauh Roof tank Linen/CSSD/Gizi dan Roof tank Irna Pada roof tank di gedung linen dan Irna ini belum ada kegiatan pembersihan roof tank secara rutin. Sehingga pembentukan biofilm ikut mencemari air yang ditampung (Ainsworth:2004). Tidak adanya akses menuju roof tank ini juga menjadi faktor pendukung mengapa roof tank ini tidak dibersihkan. Pembuatan rencana belum meliputi kegiatan pembersihan roof tank gedung linen dan Irna. Sehingga perlu perencanaan lanjut yang meliputi kebutuhan sumber daya agar kegiatan pembersihan dan 
pemantauan roof tank tersebut dapat berjalan rutin. Perencanaan ini juga harus didukung oleh perbaikan dokumen, baik dokumen prosedur dan dokumen rekaman untuk pemantauan (Simanjuktak: 2017). Secara teknis, untuk menjamin kualitas total koliform air di roof tank ini maka dapat dilakukan desinfeksi ulang.

3. Kran Terjauh Roof tank Gedung Utama

Roof tank gedung utama adalah tandon terbesar (kapasitas 3300 liter) diantara lainnya selain itu jarak dari ground tank utama ke roof tank gedung utama ini adalah yang terjauh. Rooftank ini juga mensuplai air ke roof tank gedung Irna. Dari hasil observasi diketahui bahwa lapisan internal tandon terdapat biofilm yang dapat menjadi pencemar sekunder air yang ditampung. Biofilm terjadi karena kurangnya perawatan rutin pada tandon. Perawatan yang rutin dapat dilakukan jika sumber daya yang ada mencukupi untuk melakukan kegiatan tersebut. Desinfeksi ulang juga dapat dilakukan di roof tank ini dengan menghitung debit rata-rata yang masuk ke tandon per hari.

Aliran kedua berasal dari air PDAM sebelah timur yang dialirkan langsung ke roof tank ruangan paviliun (E) dan ground tank ruangan Operasi Kamar (F). Desinfeksi ulang dari aliran ini hanya dilakukan di ground tank ruangan Operasi Kamar dengan dosis satu hingga dua tablet TCCA $90 \%$ per bulan.

Tabel 2

HASIL PEMERIKSAAN TOTAL KOLIFORM PADA ALIRAN KEDUA

\begin{tabular}{|c|c|c|c|c|c|c|}
\hline No & Sampling & Titik Sampling & $\begin{array}{c}\text { Hasil } \\
\text { (/100 mL } \\
\text { sampel) }\end{array}$ & Jarak & $\begin{array}{c}\text { Batas Maks } \\
\text { (/100 mL } \\
\text { sampel) }\end{array}$ & Ket \\
\hline 1 & \multirow{2}{*}{ Pertama } & $\mathrm{F}$ & 130 & 20 & 50 & TMS \\
\hline 2 & & $E$ & 4,5 & 21 & 50 & MS \\
\hline 3 & \multirow{2}{*}{ Kedua } & $F$ & 100 & 20 & 50 & TMS \\
\hline 4 & & $E$ & 7,5 & 21 & 50 & TMS \\
\hline 5 & \multirow{2}{*}{ Ketiga } & $F$ & 4,5 & 20 & 50 & TMS \\
\hline 6 & & $E$ & 130 & 21 & 50 & MS \\
\hline
\end{tabular}

1. Kran Terjauh Roof tank Paviliun

Aliran air dari PDAM ke roof tank gedung paviliun cukup pendek dibandingkan aliran lainnya sehingga pencemaran di sistem distribusi dapat diminimalkan. Namun karena ada satu roof tank yang tidak tertutup dapat membuat pencemar disekitar seperti binatang pengganggu, air hujan, mikroba di sekitar dapat masuk mencemari air didalamnya, bahkan dapat menjadi tempat perkembang biakan vektor. Untuk itu perlu perbaikan dan perawatan rutin agar tidak ada sarana yang rusak terabaikan. Pada aliran gedung ini juga tidak dilakukan desinfeksi ulang. Sehingga jika terjadi pencemaran pada sumber air yang digunakan maupun disepanjang sistem distribusi tidak dapat di cegah.

2. Kran Terjauh Ground Tank Gedung Operasi Kamar (Instalasi Bedah Sentral)

Sumber pencemar yang mungkin mencemari air pada aliran gedung operasi kamar dapat disebabkan oleh sumber air yang digunakan. Selain itu proses desinfeksi yang dosisnya belum diperhitungkan dengan membuat proses tersebut tidak efektif baik untuk menurunkan jumlah bakteri koliform ataupun mencegah pencemaran ulang.

Hasil observasi pada 38 poin yang telah dilakukan pada program penyediaan air bersih di RSUD Syamrabu selama bulan Juni 2017 oleh peneliti 
didapatkan hasil 19 jawaban baik dan 19 jawaban buruk. Sehingga persentasi jawaban baik adalah $50 \%$. Merujuk definisi operasional, persentase ini masuk dalam kriteria tidak memenuhi syarat yakni $<75 \%$.

Kegiatan mengenai air bersih perlu dilakukan secara rutin lain. Pemeriksaan sisa klor dalam 24 jam perlu dilakukan sebagai upaya control (Permenkes 1204 2004). Pemeriksaan sisa klor ini telah ada pada SOP namun belum terlaksana karena kurangnya sumber daya. Untuk membuat proses desinfeksi efektif maka perhitungan kebutuhan klor adalah sebagai berikut:

1. Dosis Klor Per Liter

Dosis klor per liter dapat diketahui dari jumlah daya sergap klor dan sisa klor yang diinginkan. Karena nilai daya sergap klor adalah $0,5 \mathrm{mg} / \mathrm{L}$ dan sisa klor yang diinginkan adalah $0,5 \mathrm{mg} / \mathrm{L}$ (biasanya antara $0,2 \mathrm{mg} / \mathrm{L}$ hingga 0,5 $\mathrm{mg} / \mathrm{L}$ ) sisa klor ditentukan sekian dengan pertimbangan jarak reservoar hingga titik kran cukup jauh. Sehingga dosis klor per liter adalah $1 \mathrm{mg} / \mathrm{L}$.

2. Perhitungan Kebutuhan Klor di MasingMasing Titik

Tabel 3

JUMLAH KEBUTUHAN KLOR

\begin{tabular}{clccc}
\hline No & \multicolumn{1}{c}{ Titik Desinfeksi } & $\begin{array}{c}\text { Debit Air } \\
\left(\mathrm{m}^{3} / \text { hari }\right)\end{array}$ & $\begin{array}{c}\text { Kebutuhan Klor } \\
(\mathrm{gram} / \mathrm{hari})\end{array}$ & $\begin{array}{c}\text { Kebutuhan Klor } \\
\text { (tablet/5 hari) }\end{array}$ \\
\hline 1 & Ground Tank Utama & 152,76 & 170 & 4,5 \\
\hline 2 & Ground Tank OK & 32,93 & 37 & 1 \\
\hline 3 & Roof Tank Gd. Utama & 61,1 & 68 & 1,7 \\
\hline 4 & Roof Tank Gd. Linen & 45,8 & 51 & 1,3 \\
\hline 5 & Roof Tank Gd. Irna & 45,8 & 51 & 1,3 \\
\hline 6 & $\begin{array}{l}\text { Roof Tank Gd. } \\
\text { Paviliun }\end{array}$ & 21,93 & 25 & 1 \\
\hline
\end{tabular}

\section{Kesimpulan}

Berdasarkan hasil penelitian Upaya Peningkatan Kualitas Mikrobiologi Air Bersih (Studi di RSUD Syarifah Ambami Rato Ebu Bangkalan 2017) yang telah dilakukan dapat disimpulkan bahwa:

1. Hasil pemeriksaan kualitas mikrobiologi total coliform air bersih menunjukkan hasil tidak memenuhi syarat pada 16 Maret 2017 di dua kran terjauh ground tank OK dan roof tank linen, pada 31 Maret 2017di satu kran terjauh ground tank OK, dan dapa 5 Juni 2017 di empat kran terjauh roof tank Linen, Irna, Gedung Utama, dan Paviliun.

2. Analisis hasil pemeriksaan kualitas mikrobiologi total coliform air bersih menunjukkan tidak ada titik kran yang secara konstan tidak memenuhi syarat selama tiga kali pengulangan sampling.

3. Hasil observasi aspek teknis dan manajemen dalam penyediaan air bersih tidak memenuhi syarat dengan persentase jawaban baik adalah $50 \%$.

4. Analisis observasi aspek teknis dan manajemen dalam penyediaan air bersih menunjukkan dua program yakni pemeriksaan sisa klor dan inspeksi sanitasi sarana air bersih belum pernah dilakukan.

5. Upaya yang dapat dilakukan adalah melakukan dosis desinfektan di ground tank dan melakukan pemberian klorin tablet setiap lima hari.

\section{Saran}

1. Bagi RSUD Syamrabu Bangkalan: Menambah titik pemberian klorin tablet yakni di roof tank gedung Utama, gedung Irna, gedung Paviliun, dan Gedung Linen. Melakukan kegiatan pemantauan sisa klor setiap hari serta inspeksi sanitasi sarana air bersih minimal satu kali setahun. 
2. Bagi Dinas Kesehatan Bangkalan: Melakukan uji petik air bersih di RSUD Syamrabu sesuai ketentuan Permenkes 1204 tahun 2004.

3. Bagi Peneliti Selanjutnya:

Melakukan penelitian terhadap air PDAM sebagai sumber air RSUD Syamrabu Bangkalan untuk memastikan kualitas mikrobiologi sumber air tersebut.

Melakukan penelitian terhadap kelayakan sistem plumbing di RSUD Syamrabu Bangkalan.

\section{DAFTAR PUSTAKA}

Ainsworth, Richard, 2004. Safe Piped Water: Managing Microbial Water Quality in Piped Distribution Control. London: IWA Publishing.

Centers for Disease Control and Prevention dan American Water Works Association, 2012. Emergency Water Supply Planning Guide For Hospitals And Health Care Facilities. Atlanta: U.S. Department of Health and Human Services.

Center for Disease Control and Prevention, 2009. Drinking Water. https://www.cdc.gov/healthywate r/drinking/private/wells/testing.ht ml diakses Juli 2017

Chandra, Budiman, 2007. Pengantar Kesehatan Lingkungan. Jakarta: Penerbit Buku Kedokteran EGC. Cetakan Pertama.

Da Silva, Nausely, et al, 2013. Microbiological Examination Methods of Food and Water ( $A$ Laboratory Manual). London: CRC Press.

Efendi, Hefni, 2003. Telaah Kualitas Air Bagi Pengelolaan Sumber Daya dan Lingkungan Perairan. Yogyakarta: Kanisius.
Etrawati, Fenny, 2012. Intervensi Perilaku dan Lingkungan Dalam Pencegahan Kejadian Penyakit Malaria di Indonesia tahun 2012. Buletin Spirakel, Edisi 2012: 2531.

Griffin, Donald, 2012. Hospital: What Are They and How They Work. United States, Jones \& Barlett Learning. Fourth Edition: 4-11.

Hapsari, Dwi. Sari, Puti. Pradono, Julianti, 2009. Pengaruh Lingkungan Sehat, Dan Perilaku Hidup Sehat Terhadap Status Kesehatan. Buletin Penelitian Kesehatan. 2009: 40-49. Herujito, Yayat, 2011. Dasar-Dasar Manajemen. Bogor: Grasindo. (1-3)

Kodoatie, Robert dan Syarief, Roestam, 2010. Tata Ruang Air. Yogyakarta: ANDI.

Natarajan, Sangeetha, 2010. Hospital Supportive Services. New Delhi: Excel Books.

Notoatmodjo, Soekidjo, 2014. Metodologi Penelitian Kesehatan. Jakarta: PT. Rineka Cipta. Edisi Revisi Cetakan Kedua.

Pandit, Aniruddha Balchandra. Kumar, Jyoti Kishen, 2013. Drinking Water Desinfection Techniques. New York: CRC Press.

Pizzi, Nicholas, 2010. Water Treatment (Prinsiples \& Practice of Water Supply Operation Series). Denver: American Water Works Association. Edisi Keempat.

Simanjuntak, Hasiholan, 2017. 4 Level Dokumen Dalam Sistem Manajemen Mutu. http://sentralsistem.com/news/de tail/4-level-dokumen-dalamsistem-manajemen-mutu diakses Juli 2017 